\title{
The Education of Australian School Students With the Most Severe Intellectual Disabilities: Where Have We Been and Where Could We Go? A Discussion Primer
}

\author{
Gordon Lyons and Michele Cassebohm \\ The University of Newcastle, Australia
}

\begin{abstract}
The education of Australian students with the most severe intellectual disabilities continues to present substantial challenges to policymakers, practitioners and families. These are complex and involve philosophy and ethics generally, and curriculum assessment and pedagogy specifically. In light of the various phases of development for an Australian Curriculum, the authors advocate for broad-based debate about the nature of education for these students. To prime discussion, this paper looks at the past, present and possible futures with respect to the education of Australian students with the most severe intellectual disabilities.
\end{abstract}

Keywords: severe intellectual disabilities, high support needs, curriculum, assessment, pedagogy

\section{Introduction}

In Australia, students with the most severe intellectual disabilities (MSID) are generally referred to as having 'high support needs'. They are usually grouped amongst the wider population of students with 'severe intellectual disabilities' and are mostly educated in 'special' classes and schools. These students are assessed as having an 'untestable' IQ and usually have a diversity of widely varying concomitant communicative and sensory disabilities. (Internationally, students with MSID are variously referred to as having 'profound multiple learning difficulties', 'severe handicaps' or 'profound multiple disabilities'. This latter term is preferred by the International Association for the Scientific Study of Intellectual Disabilities, the leading international organisation in the field [IASSID, 2011].)

Students with MSID find learning more difficult than others and consequently their teachers find them more difficult to teach (Bayliss, 2005; Foreman \& Arthur-Kelly, 2005; Imray, Gazquez, \& Bond, 2010). This presents a complexity of challenges, many of which extend to their families who, unlike the parents of most students, have more say in the nature of their children's education (Arthur-Kelly, Foreman, Bennett, \&

Correspondence: Gordon Lyons, School of Education, The University of Newcastle, Ourimbah, NSW 2258, Australia. E-mail: gordon.lyons@newcastle.edu.au 
Pascoe, 2008); to policymakers, who wrestle with tensions inherent in the regular-special education nexus (Sailor, 2008; Slee, 2011); and to the many others interested in the broader inclusion debate (Dixon \& Verenikina, 2007; Imray et al., 2010). These challenges are interrelated and involve philosophy and ethics generally (Hewett, 2009; Slee, 2011; Stolk, Boer, \& Seldenrijk, 2000) and curriculum assessment and pedagogy specifically (Bayliss, 2005). Although not uncontentious, the reasoning and justification for children and young people with MSID to be educated is generally accepted (Stolk, 2000). In contrast, the nature of curriculum pedagogy and assessment for these students is historically contentious (Ware \& Donnelly, 2004).

The development of the Australian Curriculum throws a spotlight on these issues. According to the Australian Curriculum Assessment and Reporting Authority (ACARA), students with 'special education needs' will be granted 'appropriate adjustments' in terms of content and assessment. Students with a 'significant intellectual disability', unable to benefit from these adjustments, will be provided with 'additional curriculum content and achievement standards ... in order to develop an Australian Curriculum that is inclusive of every learner' (ACARA, 2010, p. 4). The nature of these provisions is (at the time of writing) only partly known to the profession and the public (ACARA, 2011). Indications are though that these students will not be engaging with the 'common' curriculum and that they will be the only students for whom specific provisions/alternative curriculum will be developed and probably mandated. It is the authors' view that this raises philosophical and ethical issues with respect to curriculum, pedagogy and assessment, particularly given the relevance of the 2005 Disability Standards for Education. Subsequently, a brief review of the evolution of school education for students with MSID follows to provide a broad context for the readership to consider and debate: current philosophical and ethical positions, current policies and practices, the position of and directions taken by the Australian Government in the Australian Curriculum, and possible future pathways for the education of Australian students with MSID.

\section{The Past to the Present ... .}

Prior to the 20th century, education for people with MSID was essentially nonexistent. Individuals were frequently subjected to infanticide and euthanasia (Hogg, 2007) if they otherwise did not die as a result of their acute medical frailty. They have been referred to as the 'forgotten citizens in the world' (Chen, 2008). People with MSID were widely disregarded as sub- or non-human (Lachs, 1986) and regarded as incapable of participating in the usual activities of daily living.

During the first half of the 20th century, people with MSID were mostly committed to residential institutions (Foreman, 2011; Konza, 2008). Most of these were sponsored by religious organisations that at least practised a congregate care approach. Despite the emergence of legislation for compulsory school education, none was available to those with MSID. During this period the eugenics movement gained momentum. Supporters called for the use of forced sterilisation and even euthanasia to 'cull out' humans who were regarded as defective (Black, 2003). With the rise of the sciences of psychology and psychiatry, terms such as 'moron' and 'idiot' emerged to classify persons with MSID who were regarded to be untrainable or custodial: fit for care but not for education (Bray, Macarthur, \& Ballard, 1988).

The second half of the 20th century saw the emergence of the rights and equity movements for disadvantaged groups (Foreman, 2011). The principles of social role valorisation, normalisation and least restrictive environment found public and political 
support leading to the deinstitutionalisation movement in the human services sector and the special education and integration movements in the education sector (Konza, 2008). At the same time, public conceptions of disability moved somewhat from the personal tragedy model, to the medical model, and then to the social model of disability (Sailor, 2008). This led to legislative changes that afforded more equitable rights of access and participation to those with disabilities (Dempsey, 2011). These changes, however, proffered more limited discernible benefit to those with MSID. Public special schools for students with intellectual disabilities, including some with MSID, were established. With tightening government regulations surrounding the provision of funding, the prevailing care paradigm eventually transformed to the education paradigm and a professional acceptance of the principle that all children were educatable took hold (Simmons \& Bayliss, 2007). During the latter part of the 20th century, the disability studies movement found considerable traction in the public arena, whereas in education the discourses of mainstreaming and integration took precedence (Connor, Gabel, Gallagher, \& Morton, 2008).

In the early 21 st century discourses of inclusion became the driving ideology to impact students with disabilities (Arthur \& Foreman, 2002; Bain \& Lancaster, 2006). These discourses, although still contested, generally advocated inclusive but differentiated approaches to placement, curriculum, pedagogy and assessment for students with disabilities (Ferguson, 2008), and they gained momentum through policy and legislative developments at the national and international levels (Dixon \& Verenikina, 2007). In short, the international consensus was that students with disabilities had the same rights to education as others (Konza, 2008; Slee, 2011).

At the international level, UNESCO promulgations like the 1948 Universal Declaration of Human Rights, the 1980 Convention against Discrimination in Education, the 1989 Convention on the Rights of the Child, the 1994 Salamanca Statement and Framework for Action in Special Needs Education, the 2006 Convention on the Rights of Persons with Disabilities and, most recently, the 2009 Policy Guidelines on Inclusion in Education are exemplars (European Agency for Development in Special Needs Education, 2009). At the national level the rationale for students with MSID to be educated precipitated out of these international declarations and policies. Consequently, the nature of education for students with MSID varied widely. Indeed, despite the evidently encouraging international consensus that inclusion is the most influential contemporary philosophy, practices vary widely and are generally less inclusive than the philosophy and rhetoric suggested (Konza, 2008; Slee, 2011).

Australian students with MSID mostly have a collaboratively negotiated individualised education program (IEP) based on their additional educational needs (Dowrick, 2001). Most are educated in segregated special schools, although some have placements in special and regular classes in regular schools (Konza, 2008). Different interest groups, however, support different placement priorities for a variety of reasons (e.g., Dempsey, 2011; Foreman, 2011; Rogers, 2007; Siegal \& Allinder, 2005; Soresi, Nota, \& Wehmeyer, 2011). Placement options, however, are restricted if an enrolment involves a reasonable expectation of unjustifiable hardship arising from excessive resource demand and/or deleterious infringement on the educational opportunities of other students (Dempsey, 2003). National and state disability legislation like the 1992 Disability Discrimination Act (Commonwealth of Australia Consolidated Acts, 1992) and 2005 Disability Standards for Education (Commonwealth of Australia, 2006) (the latter being currently under review; Garrett, 2011) is obviously important and pertinent (NSW Disability Discrimination Legal Centre Inc., 2010). 
Curriculum pedagogy and assessment are widely acknowledged as three key interdependent elements of school education for all students (Brady \& Kennedy, 2010; Killen, 2005). The next sections of this paper elucidate these historically in regard to students with MSID.

\section{Curriculum}

Up until around the mid 20th century, curriculum was essentially nonexistent in that most of the engagement between staff and students was care-related. Staff provided personal care and support in activities of daily living, like eating, toileting and washing, implemented therapy regimes and treatments, and then facilitated passive recreational engagement (National Dissemination Center for Children with Disabilities, 2011). Staffing levels were much lower than today so these students spent frequent periods being physically cared for and long periods passively engaged in recreational activities. As they did not have the skills (or possibly the motivation or alertness) to proactively engage in constructive self-directed recreational activities, meaningful engagement was usually limited to when one-on-one support was available (Bray et al., 1988). Furthermore, the expectations of many staff for the growth and development of these students was limited, so it is not surprising that the majority of their time probably passed in a non-alert state, with boredom or frustration leading to pervasive self-stimulatory and challenging behaviours (Foreman, Arthur-Kelly, Pascoe, \& Smyth King, 2004).

During the 1960s special educators, encouraged by an increasing awareness of their students' rights and capabilities to learn, introduced 'developmental' curricula. Students were instructed in skills that were appropriate to their mental age, with the belief and expectation that any learning would follow normal developmental pathways. This model was conceptually limited by the belief that individuals with MSID would not develop beyond the early childhood stage (Nietupski, Hamre-Nietupski, Curtin, \& Shrikanth, 1997). Developmental assessments of that time frequently referred to these individuals as having a cognitive, mental, emotional or social age equivalent to that of an infant or young child. Although this belief underpinned contemporary curricula, it was somewhat counterproductive because it did not recognise the reality that infants with MSID did grow into adulthood regardless of their cognitive impairments (Loftus, Ware, \& Donnelly, 2005).

The model was constrained because prescribed focus skill sets lacked functionality and authentic application and were often age-inappropriate (Smith, 1996). It also limited instruction in key areas like communication because it did not support progression without the establishment of supposed prerequisite skills. There was a heavy emphasis on behaviour change using applied behaviourist interventions, these already having found wide application in services for adults with intellectual disabilities. Much of the impetus for this was about moderating challenging behaviours rather than teaching adaptive skills to facilitate better communication and engagement (Butterfield, Arthur, \& Sigafoos, 1995). With the medical model of disability prevailing and the increasing use of formal psychometric assessments the developmental model, despite its limitations, found widespread application (Sailor, 2008).

The mid 1970s saw the emergence of the 'functional' model of curriculum. The notion of 'criterion for ultimate functioning' provided structure for a core curriculum based on the development of functional and authentic knowledge and life skill sets in the home, school and community (leisure and vocation) domains. This aimed to empower students to access (and function as independently as possible) in these environments (Nietupski et al., 1997). As part of the IEP development and review process parents and caregivers now negotiated priorities and emphases for various aspects of the core curriculum for 
their child (NSW Department of Education and Training [NSW DET], 2005). This model was well supported by policymakers and practitioners who recognised its practicality and authenticity (NSW DET, 1991). (The 1988 NSW Curriculum Statement for Students with Severe Intellectual Disability is one exemplar.) Behaviour change still remained a significant part of this curriculum, but improving instructional technologies informed by the science of applied behavioural analysis (ABA) meant that more beneficial outcomes were achieved. Researchers and practitioners did, however, question the diminished popularity of developmental curricula because students with MSID were often able to benefit from the less 'sophisticated' learning experiences it proffered (Imray, 2011).

In the 1990s, mainstreaming and integration philosophy and practices gained precedence and so the conceptualisation of functional skills shifted to 'fit' in better with mainstream curriculum. This shift provided mainstream teachers with the opportunity to better understand the educational needs of students with disabilities in a more familiar and conventional context and also to facilitate the integration of students with less severe intellectual disabilities into their classrooms (Westwood \& Graham, 2003). But this also meant that special education teachers had to adapt their functional curricula to align with more academic curricula (Nietupski et al., 1997). The provision of IEPs still provided for the more needs-focused and individualised curricula elements for students with MSID like individualised behaviour, therapy and primary care programs (Konza, 2008). IEPs though were more often seen as 'special education business' (Jones, 2010), which compromised the movement for mainstream teachers to take at least collaborative (if not primary) responsibility for these students (Ryndak, Moore, Orlando, \& Delano, 2008).

Engaging students with MSID with mainstream curricula was for many teachers 'too tall an order' and thus contributed to a widening divide between theorists, policymakers and practitioners (Konza, 2008). Although there were some successes in early school settings, as students progressed to more senior years this (theoretical and practical) divide became arguably irreconcilable (Imray et al., 2010). Even alternative curricula designed specifically for high school students with (severe) intellectual disabilities like the NSW Life Skills courses were essentially inappropriate for and inaccessible to most students with MSID. (Indeed, inappropriate curricula are widely regarded to be a major contributor to failed inclusion [Avissar, 2010; Dempsey, 2011].) Nevertheless, two areas of strong consensus in curriculum for students with MSID are the need to develop communication and social skills. These enable individuals to communicate needs, wants and preferences, and frequently contribute to the moderation of challenging behaviours (Balandin \& Duchan, 2007; Barber, 2011).

UK school systems responded to similar difficulties by developing initiatives like the English P Levels (Qualifications and Curriculum Development Agency, 2011), the Welsh Routes for Learning initiative (Welsh Assembly Government, 2006a, 2006b) and the Northern Ireland Quest for Learning initiative (Government of Ireland, 2006). These guide teachers in developing curricula, IEPs and assessment outcomes for students who are unable to meet core requirements (Government of Britain, 2009). These initiatives, widely referred to as 'assessment' matters, highlight the critical relationship between curriculum and assessment and more particularly between common (inclusive) curriculum and assessment requirements (Pepper, 2007).

\section{Pedagogy}

Pedagogy for students with MSID has a short history. Up until around the mid 20th century the care paradigm prevailed (Bray et al., 1988). It was not until the 1960s when 
the developmental model of curriculum emerged that instructional techniques became subject to substantial professional scrutiny. Until about this time, these children and young people were considered untrainable (let alone educable), so the role of staff was to provide primary care rather than to teach per se.

The emergence of the developmental model of curriculum was widely informed by contemporary early childhood education theory and practice, which itself was less developed than that typical to regular school education. The associated pedagogy was underdeveloped because pre-service and in-service training for teachers of students with MSID was very limited (Nietupski et al., 1997). Most were only qualified for regular primary school teaching. Notwithstanding that some evidence-based practices are common to regular and special education, teaching students with MSID does present unique challenges (Jones, 2010).

With the rise of the functional model of curriculum in the 1970s and professional recognition of its diverse pedagogical demands, pre-service and in-service training for special educators became more commonplace. At the same time, the deinstitutionalisation movement for adults with intellectual disabilities saw a rise in the demand for training in ABA techniques to moderate challenging behaviours. Knowledge about these techniques became more accessible to special educators, many of whom focused their teaching on the development of observable functional skills (Bray et al., 1988). There was, however, less emphasis on the development of students' non-observable cognitive processes, which are now understood to be critical to competent learning, especially around emotional and social development (Nietupski et al., 1997). The pedagogy around IEP design and implementation also improved greatly with an increasing recognition of the need to plan collaboratively (Centre for Developmental Disability Studies, 2004). Although best practices at this time (which emphasised the operant learning of functional skills) were achieving creditable outcomes (Browder \& Cooper-Duffy, 2003), a body of criticism emerged arguing that some of this progress was at the expense of essential cognitive skill development (Bray et al., 1988; Jackson, 1993; Sabatino, Miller, \& Schmidt, 1981). This criticism particularly applied to the teaching of communication skills, an essential component in any curriculum for students with MSID (Butterfield et al., 1995). Jackson (1993) argued that developmental approaches were essential for pedagogical efficacy, while Nelson, van Dijk, McDonnell, and Thompson (2002) supported an emphasis on the teaching of cognitive skills.

In the 1990s integration and ultimately inclusion took philosophical precedence (Slee, 2011). A worldwide policy shift towards common inclusive curricula put considerable pressure on special educators to share their specialised pedagogical knowledge with mainstream colleagues who were increasingly being called upon to teach students with intellectual disabilities (Foreman, 2011). Notwithstanding that best practice for students with intellectual disabilities was widely viewed as 'special education business' (Jones, 2010), a growing collaboration of theorists and practitioners from both special education and mainstream backgrounds drew attention to a core commonality; that is, good differentiated pedagogy was good for all students (Dixon \& Verenikina, 2007; Killen, 2005). Pragmatics required that group-oriented pedagogy prevailed in mainstream classrooms for mainstream students but differentiated practices were best for students with additional needs (Snell, 2008). Another major pedagogical change to accompany the emergence of the integration and inclusion movements was the development of instructional activities focused on communication, relationships and social skills (Hewett, 2009). Nevertheless teaching students with MSID, most of whom were pre-intentional communicators, did require specialised pedagogical content knowledge and skills (Imray et al., 2010). 
The recent research and policy focus on evidence-based practice has seen a resurgence of professional interest in examining and improving pedagogy (Killen, 2005). It is widely acknowledged that teachers and the quality of their pedagogy are the strongest variables affecting student learning. Evidence-based teaching leads to better learning (Foreman, 2011) and special education in Australia and internationally already benefits from some consensus on what constitutes good practice (Carter, Stephenson, \& Strnadová, 2011). Although early conceptualisations of Authentic Pedagogy, Productive Pedagogy and the NSW Quality Teaching model of pedagogy were not exclusive of any student groups, their relevance to students with MSID was and is still debated. Prominent Australian researchers such as Stephenson (2006) argue that the 'intellectual quality' focus of the NSW Quality Teaching model has relevance to the development of cognitive and communication skills in students with MSID. An opposing view has been put forward by Formosa and Dixon (2004), who were sceptical of its relevance to students with (more severe) intellectual disabilities.

\section{Assessment}

Changes in curriculum (models) usually require changes in pedagogical practices, and these in turn require changes in assessment practices (Browder, Spooner, Wakeman, Trela, \& Baker, 2006). Changes in pedagogical theory and practice provide opportunities for curriculum development, which in turn call for changes to assessment (Ewing, 2010). These three key aspects of educational theory and practice are richly interrelated (Killen, 2005). For students with MSID who need a very student-centred education, the pedagogical demands put on their teachers are often very specific and require considerable special expertise and student knowledge (Bauder \& Simmons, 2005; Bray et al., 1988), so discussions about assessment are critical (Browder, Spooner, \& Bingham, 2004). Assessment can be summative (to inform initial and final curricula and pedagogical decisions) and formative (to inform ongoing monitoring) (Donnelly, 2005). It informs the setting of outcomes and competencies, program reviews and achievement benchmarks and also informs accountability systems about teacher performance and student learning outcomes at the individual, group and cohort levels (Killen, 2005).

For students without intellectual disabilities, broad performance benchmarks like endof-term assessment tasks and biannual national testing are generally reasonably indicative of individual and cohort progress and teaching efficacy, but for students with MSID a diversity of assessments is critical to evidence-based practice and best outcomes (Dowrick, 2002). Their learning needs are idiosyncratic and learning improvements incremental so frequent individualised assessments are essential (Bray et al., 1988). For many years, excellent special educators informed by their training in ABA have used incremental performance data to guide their instructional planning and practices. Indeed, special educators spearheaded the development of curriculum-based assessment and programming, which underpins evidence-based practice (Arthur-Kelly, 2008).

Contemporary international policy generally supports the teaching of all students using common inclusive curricula and assessment processes (Browder et al., 2006; Pepper, 2007). In the United States, the emerging requirement for all students to be performance benchmarked on common assessment scales has precipitated considerable criticism (Dempsey, 2003). Indeed, even the validity of these assessment practices has been widely challenged (Qualifications and Curriculum Development Agency, 2009). In Great Britain the implementation of the National Curriculum has faced similar criticisms (Imray, 2011). UK governments responded by developing alternative 'pre-foundation' assessment scales (with wide curricula and pedagogical implications) for those students unable to achieve the first 
level of academic achievement (Government of Britain, 2009). Despite this initiative, most students with MSID were still unable to participate meaningfully so further assessment guidelines were developed to deliver meaningful comparisons of performance goals and learning outcomes (Hewett, 2009; Loftus et al., 2005). Given that most students with MSID have an IEP, the meaning, relevance and value of comparative cohort assessment remains tenuous (Imray, 2011). Clearly, in the international milieu the principles of inclusion steer policy and practice development in the education of students with disabilities (Slee, 2011).

Although in educational and other social contexts inclusion prevails as the goal to which most nations aspire, the realities of diverse interpretations and shortages in human and financial resources mean that it remains an unlikely outcome for many. For most students with MSID, who are widely regarded as amongst the most difficult to educate, inclusion does seem unlikely. Curriculum pedagogy and assessment theory and practices relating to students with MSID are diverse, and given that very different legislative and policy contexts prevail (Dixon \& Verenikina, 2007), consistent and widespread evidence-based policy and practice is unlikely to do so (Imray, 2011).

In Australia, like in many countries, diverse interpretations of inclusion generally and of pertinent government legislation, policy and procedures specifically means that educational policy and practice at state, regional and local levels is also diverse (NSW Disability Discrimination Legal Centre, 2010; Sigafoos et al., 2010). For students with MSID, evidence-based practice is not consistently the norm (Carter et al., 2011) and a variety of restraints and barriers are complicit. These include, for example, inadequate funding, staffing, teacher expertise and support services (Australian Teacher Education Association, 2006; Konza, 2008; Public Schools Principals Forum, 2009); attitudinal barriers amongst staff, students and the wider community (NSW Disability Discrimination Legal Centre, 2010); the regular-special education nexus (Slee, 2008); inadequate collaboration (Forlin, Loreman, Sharma, \& Earle, 2009); discordant curriculum pedagogy and assessment (Roberts \& Ridley, 2009); wide diversity of individual disabilities and needs (Dowrick, 2002); and inconsistent definition (Dempsey, 2003).

At the same time there is considerable 'corporate knowledge' about what is needed to improve outcomes for students with disabilities generally (Arthur \& Foreman, 2002; Australian Association of Special Education, 2010; Renzaglia \& Dymond, 2005). There is a reasonable research base informing developments in inclusive policy and practice and the education of students with disabilities in Australia, some of which has relevance to students with MSID. For example, explicit systematic and data-based instruction and assessment (Dowrick, 2002); the use of augmentative and alternative communication technologies (Hewett, 2009); collaborative approaches to planning (Centre for Developmental Disability Studies, 2004); student-centred planning; behaviour state assessment (Foreman \& Arthur-Kelly, 2005); ABA and positive behaviour support (Clarke, Worcester, Dunlap, Murray, \& Bradley-Klug, 2002; Munde, Vlaskamp, Ruijssenaars, \& Nakken, 2011); curriculum-based assessment and programming (Loftus, et al., 2005); school renewal (Bain \& Lancaster, 2006; Konza, 2008); increased, flexible government funding (Konza, 2008); professional development (Carroll, Forlin, \& Jobling, 2003); and a curricula focus on communication and social skills development (Hewett, 2009).

As aforementioned, the majority of Australian students with MSID are educated in special schools or classes by 'special education' teachers. Prevailing policies support the provision and maintenance of enrolment options for these students, and although some states have taken the initiative to deliver educational services under one inclusive milieu, 'special education' and its infrastructure predominates. Most students with MSID have an individualised needs-based curriculum delivered in the context of their IEP and this 
often bears little resemblance to the common curriculum mandated for the vast majority of students.

\section{The Present to the Future ... .}

The nature of (special) education for students with disabilities continues to come under question, particularly in the context of the inclusion debate (Australian Association of Special Education, 2010; Simmons \& Bayliss, 2007; Slee, 2011; Smith, 2007). Intended outcomes and learning goals for students with MSID are often so individual and their post-school lives so different from those anticipated for most of their same-age peers (due to their lifelong dependence in all activities of daily living) it might be said that the nature of their education is in some ways fundamentally different from that of most other students (Lyons, 2003).

Up to this point this paper has reviewed the evolution of education for Australian school students with MSID. Where to now? What might inform debate about new directions and developments in the education of students with MSID? This final section suggests seven theoretical pathways for the education of Australian school students with MSID. It is not an exhaustive list and the pathways are not necessarily mutually exclusive, but they are intended to provide the readership with a diversity of options for stimulating debate about future developments in the education of students with MSID.

The first 'status quo pathway' means just 'staying the current course'. If this pathway were followed, Australian students with MSID would generally continue to receive their education in segregated settings with small heterogeneous groups of peers with similarly individual high support needs. Curriculum and assessment would remain individualised and articulated through a negotiated IEP. Pedagogical decision-making would essentially remain the teachers' prerogative. This pathway is not synchronous with the worldwide trend towards educational inclusion generally or with the principles of the impending Australian Curriculum but could find substantial support amongst both special and general educators and families who are reasonably satisfied with the status quo.

The second 'immersion pathway' would lead to placement of all students with MSID in regular 'local' classes in fully inclusive school systems with some individual/group withdrawal for focused teaching/learning activities. Curriculum, pedagogy and assessment practices would be differentiated to meet the individual needs of all students in each class/cohort and additional support provided to address issues of equity and access. External benchmark assessments would be modified for individual students with appropriate 'accommodations'. This pathway aligns reasonably with the principles of inclusion and is philosophically and ethically equitable. It aligns with the 2008 Melbourne Declaration, particularly the educational goals for young Australians (Ministerial Council on Education, Employment, Training and Youth Affairs, 2008) and the scope and shape of the Australian Curriculum (as promulgated at the time of writing). Most of the previously mentioned restraints and barriers would still hinder progress along this pathway. Nevertheless there are precedents. As previously mentioned, Scandinavian countries generally practice 'full' educational and social inclusion. The Finnish Government claim that the 'state of inclusion has already been achieved' (Saloviita, 2009) notwithstanding that special education services still support some students (Karakoski, 2008). A similar pathway has been taken by a number of large regional educational jurisdictions in Canada. This pathway would likely have substantial 'in principle' support (Dixon \& Verenikina, 2007) but might well be resisted by a 'pragmatic' opposition who identify resilient restraints and insurmountable barriers. 
The third 'strategic inclusion pathway' would lead to placement of all students with MSID in support classes in regular local schools in fully inclusive school systems with strategic engagement with regular classes. A progressive interpretation of 'least restrictive environment' applies here. Curriculum, pedagogy and assessment practices in the base support class would be developed within an IEP rubric and in regular class engagement within a differentiated rubric. Additional supports would be provided to address issues of equity. External benchmark assessments would be modified for individual students with appropriate 'accommodations'. This pathway aligns partly with the principles of inclusion. The 2008 Melbourne Declaration and the Australian Curriculum are also relevant. As with the immersion pathway above various restraints and barriers would hinder progress. There are broad precedents for taking this pathway. In the USA, for example, federal government legislation effectively mandates inclusion 'in the least restrictive environment' along with the provision of an appropriately negotiated and resourced IEP (Boyd, Seo, Ryndak, \& Fisher, 2005). This pathway should have strong 'in principle' support but also be resisted by a 'pragmatic' opposition.

The fourth 'opportunistic inclusion pathway' would lead to placement of all students with MSID in support classes in still segregated school systems with (only) opportunistic engagement in regular education activities and curriculum, pedagogy and assessment practices. A less progressive interpretation of 'least restrictive environment' applies here. Curriculum, pedagogy and assessment practices in the home support class would be developed within a best practice IEP rubric and any regular education engagement and additional supports would be provided to facilitate enhanced achievement of IEP goals/intended outcomes (Imray, 2011). External benchmark assessments would not apply. This pathway hardly aligns with the principles of inclusion. The 2008 Melbourne Declaration and the Australian Curriculum are tenuously relevant. Known restraints and barriers would variously impact progress. There are precedents for taking this pathway. In the UK (like Australia) there is a cascade of placement options for students with MSID including regular class, special class and (mostly) special school placements. The countries of the UK have their own curriculum, but in recognition of the failure of these to meet the needs of students with MSID, they have developed and introduced common curricula and assessment guidelines specifically for these students. These guidelines (i.e., the English 'P' Levels, the Welsh Routes for Learning documents, and Northern Ireland's Quest for Learning documents) 'preface' the national curricula. That is, students who achieve benchmarks progress to the respective foundation level(s) in the common curricula.

The fifth 'residential schools pathway' is a more restrictive variant (Boban \& Hinz, 2010). This would lead to the segregation of students with MSID into residential schools (McGill, Tennyson, \& Cooper, 2006; Roberts \& Ridley, 2009). This (albeit unlikely pathway in the Australian context) would lead to all students with MSID being placed in residential schools wherein a '24/7 IEP' would be implemented across 'controlled' school, home and community settings. Clearly there would be widely opposing philosophical, ethical, pedagogical and pragmatic views on '24/7 IEPs' for students with MSID in Australia notwithstanding that residential schools are quite common in many other countries and an emerging trend in Great Britain is to support these placements 'in the best interests' of the students and their families (McGill et al., 2006). In this pathway, the main variables are placement and pedagogy, although curriculum and assessment might remain essentially the same.

The sixth 'multiple intelligences pathway' is an alternative approach to curriculum design and implementation. This would entail a significant restructuring of curriculum (and hence pedagogy and assessment) practices in order to focus on Gardner's multiple 
intelligences theory (Krause, Bochner, Duchesne, \& McMaugh, 2010). Although well known and moderately popular as a pedagogical approach in regular education (Kosky \& Curtis, 2008), there is considerable controversy about its legitimacy and application (Gardner \& Traub, 1999). Its suggested use with students with intellectual disabilities is quite different and would most probably require segregated placement (Clarke et al., 2002; Perez \& Dominguez, 2005).

The seventh 'quality of life pathway' is an alternative approach to curriculum design and development. Following this pathway would entail a significant restructuring of curriculum, pedagogy and assessment practices to align with the goals and outcomes advocated by proponents of quality of life referenced service delivery (e.g., Bayliss, 2005; Lyons \& Cassebohm, 2011) who argue that the overarching goal of education for students with MSID should be to improve their continuing quality of life (QOL) by providing them with educational experiences and instruction which improve their ability to experience life satisfaction and happiness (Lyons, 2004). There is wide 'in principle' support in the extant literature for this pathway (and theory) generally (Shearer, 2010), as well as practice precedents for students with MSID (Bayliss, 2005; Longhorn, 2002; Ware \& Donnelly, 2004). Bayliss (2005), for example, describes initiatives taken by a group of UK schools for students with MSID to introduce curricula specifically focusing on the development of QOL. Most curriculum documents (including the Australian Curriculum) include a preface of educational goals that make reference to improving overall (present and future) QOL. School systems (with government funding support) are taking an increasing interest in teaching about happiness and wellbeing (Morris, 2009; Pagliano, 2006; Smith, 2010). Happiness, wellbeing and QOL are also emerging as guiding principles in the development of support services for adults with intellectual disabilities in Australia and worldwide (Gómez, Verdugo, Arias, \& Arias, 2011; Lyons, 2010; Vos, De Cock, Petry, Van Den Noorgate, \& Maes, 2010). This curricula focus is intended to guide the design of appropriate person-centred planning for students (and adults) with MSID (Lyons, 2003). A premise would be that appropriate developmental and functional curricula elements would still be included in any person-centred plan but that a clearer and more emphatic focus on QOL improvement should prevail (Ware \& Donnelly, 2004). This pathway could have strong 'in principle' support from a diversity of interest groups.

\section{Conclusion}

The education of students with the most severe intellectual disabilities poses a diversity of challenges and conundrums for educators, parents and policymakers, particularly in the context of the national and international movement towards inclusive education and the ongoing development of the Australian Curriculum. The nature of education for these students is confounded by the regular-special education nexus, an artifact of the relatively short history of education for this small heterogeneous group of students. For Australian students with MSID particularly, the nature of the Australian Curriculum is centrally important. It is clearly put forward as an inclusive curriculum but it currently shows limited capacity to address the particular needs of these students. Where to now for Australian school students with MSID? How might different scenarios impact these students - and teachers, policymakers and families? It is the authors' view that a broadbased discussion on the education of these students is timely. These students appear to be the 'odd ones out' in the draft Australian Curriculum, at least as implied in the few pertinent (ACARA) documents currently available to the public and profession. 
In attempt to stimulate discussion and prime debate on this topic this paper firstly presented a brief review of the 'evolution' of Australian school education for these students, focusing on curriculum, pedagogy and assessment. It is a widely acknowledged truism that a good understanding of the past best informs deliberations about the future. Does this history match your knowledge and understanding? Does this history provide you with a more informed view of the present state of education for these students? Does this history suggest to you where the education of these students should go in the shorter- and longer-term futures? What challenges does this history pose for you (and others) in terms of philosophy, ethics, policy and practice?

This paper then hypothesised seven pathways for the development of education for students with MSID. Do these represent a reasonable 'cross-section' of options? Are any more or less likely (in the shorter or longer term) given the current Australian (and international) sociocultural, political and economic landscapes? How synchronistic are these with your personal, professional and/or organisational philosophies, policies and practices? What are the primary restraints, barriers and facilitators to these pathways and what actions might be taken to impact these? What (academic and action) research initiatives might be taken to investigate the potential 'viability' of these (and any other) futures for educating Australian school students with MSID? Do other aspects of international experience/research (better) inform deliberations about the education of these students?

Any one pathway is unlikely to address the challenges facing these students and their parents, teachers and educational policymakers, and each would have advocates and critics. Consequently, it seems timely that interested parties should collaboratively discuss and debate this topic. How might this be facilitated (at school, community, organisational and government levels)? It is hoped that this paper might at least prime this discussion.

\section{References}

Arthur-Kelly, M. (2008). Planning effective teaching strategies. In P. Foreman (Ed.), Inclusion in action (2nd ed., pp. 164-197). Melbourne, Australia: Thomson.

Arthur-Kelly, M., Foreman, P., Bennett, D., \& Pascoe, S. (2008). Interaction, inclusion and students with profound and multiple disabilities: Towards an agenda for research and practice. Journal of Research in Special Educational Needs, 8, 161-166. doi:10.1111/j.1471-3802.2008.00114.x

Arthur, M., \& Foreman, P. (2002). Educational programming for students with high support needs: Report data from teachers, paraprofessionals and other professionals working in Australian schools. Developmental Disabilities Bulletin, 30, 115-139.

Australian Association of Special Education. (2010, July). The Australian Curriculum. AASE News.

Australian Association of Special Education. (2011, April). President's report. AASE NSW Chapter Newsletter.

Australian Curriculum, Assessment and Reporting Authority (ACARA). (2010, November). ACARA's response to the consultation feedback on the draft K-10 Australian Curriculum. Sydney: Author.

Australian Curriculum, Assessment and Reporting Authority (ACARA). (2011, September 22). Welcome to the ACARA update, 2011(32). Sydney: Author.

Australian Teacher Education Association. (2006, July). Making teaching public: Reforms in teacher education. Proceedings of the 34th Australian Teacher Education Association National Conference, Fremantle, Western Australia.

Avissar, G. (2010). Inclusive curriculum planning and implementation: Taking a second look at teachers' curricular activities. Unpublished manuscript. 
Bain, A., \& Lancaster, J. (2006). Inclusion and comprehensive school reform: Lessons from the field. Australasian Journal of Special Education, 30, 39-50. doi:10.1080/10300110609409364

Balandin, S., \& Duchan, J.F. (2007). Communication: Access to inclusion [Editorial]. Journal of Intellectual \& Developmental Disability, 32, 230-232. doi:10.1080/13668250701693902

Barber, M. (2011, March). Communicate, participate, enjoy!... then communicate some more! Paper presented at the SCOPE 'Communicate, Participate, Enjoy! Solutions to Inclusion' Conference, Melbourne, Australia.

Bauder, D.K., \& Simmons, T.J. (2005, August). UDL approaches to an inclusive education. Paper presented at the ISEC 2005 Conference, Glasgow, Scotland.

Bayliss, P. (2005, August). Peter, Katie and Billy: Including children with significant support needs. Paper presented at the ISEC 2005 Conference, Glasgow, Scotland.

Black, E. (2003). War against the weak: Eugenics and America's campaign to create a master race. New York, NY: Four Walls Eight Windows.

Boban, I., \& Hinz, A. (2010). Symposium: Working on the basis of the Index for Inclusion in one of the most segregated parts of the world's educational systems - the German speaking countries. Unpublished manuscript.

Boyd, B.A., Seo, S., Ryndak, D.L., \& Fisher, D. (2005, August). Inclusive education for students with severe disabilities in the United States: Effects on selected areas of outcomes. Paper presented at the ISEC 2005 Conference, Glasgow, Scotland.

Brady, L., \& Kennedy, K. (2010). Curriculum construction (4th ed.). Frenchs Forest, Sydney: Pearson Australia.

Bray, A., Macarthur, J., \& Ballard, K.D. (1988). Education for pupils with profound disabilities: Issues of policy, curriculum, teaching methods, and evaluation. European Journal of Special Needs Education, 3, 207-224. doi:10.1080/0885625880030403

Browder, D.M., \& Cooper-Duffy, K. (2003). Evidence-based practices for students with severe disabilities and the requirement of accountability in "No Child Left Behind". The Journal of Special Education, 37, 157-163. doi:10.1177/00224669030370030501

Browder, D.M., Spooner, F., \& Bingham, M.A. (2004). Current practices in alternate asessment and access to general curriculum for students with severe disabilities in the United States of America. Australasian Journal of Special Education, 28, 17-29. doi:10.1080/1030011040280203

Browder, D.M., Spooner, F., Wakeman, S., Trela, K., \& Baker, J.N. (2006). Aligning instruction with academic content standards: Finding the link. Research and Practice for Persons with Severe Disabilities, 31, 309-321.

Butterfield, N., Arthur, M., \& Sigafoos, J. (1995). Partners in everyday communicative exchanges: A guide to promoting interaction involving people with severe intellectual disability. Sydney, Australia: MacLennan \& Petty.

Carroll, A., Forlin, C., \& Jobling, A. (2003). The impact of teacher training in special education on the attitudes of Australian preservice general educators towards people with disabilities. Teacher Education Quarterly, 30(3), 65-79.

Carter, M., Stephenson, J., \& Strnadová, I. (2011). Reported prevalence by Australian special educators of evidence-based instructional practices. Australasian Journal of Special Education, 35, 47-60. doi:10.1375/ajse.35.1.47

Centre for Developmental Disability Studies. (2004). Client participation in the individual planning process (Final Report). Sydney, Australia: Department of Ageing, Disability \& Home Care. Retrieved March 2011 from http://www.adhc.nsw.gov.au/_data/assets/file/0007/228184/ 31_ClientparticipationintheIndividualPlanningProcess.pdf

Chen, N.C. (2008, May). From forgotten to being remembered. Paper presented at the 2008 IASSID 13th World Congress, Capetown, South Africa.

Clarke, S., Worcester, J., Dunlap, G., Murray, M., \& Bradley-Klug, K. (2002). Using multiple measures to evaluate positive behavior support: A case example. Journal of Positive Behavior Interventions, 4, 131-145. doi:10.1177/10983007020040030201 
Commonwealth of Australia. (2006). Disability Standards for Education 2005. Retrieved from http:// www.deewr.gov.au/schooling/programs/pages/disabilitystandardsforeducation.aspx

Commonwealth of Australia Consolidated Acts. (1992). Disability Discrimination Act 1992. Retrieved from http://www.austlii.edu.au/au/legis/cth/consol_act/dda1992264/

Connor, D.J., Gabel, S.L., Gallagher, D.J., \& Morton, M. (2008). Disability studies and inclusive education: Implications for theory, research, and practice. International Journal of Inclusive Education, 12, 441457. doi:10.1080/13603110802377482

Dempsey, I. (2003). The impact of the Disability Discrimination Act on school students with a disability in Australia. Australia and New Zealand Journal of Law and Education, 8(1), 35-44.

Dempsey, I. (2011). Legislation, policies and inclusive practices. In P. Foreman (Ed.), Inclusion in action (2nd ed., pp. 37-62). Melbourne, Australia: Cengage.

Dixon, R.M., \& Verenikina, I. (2007). Towards inclusive schools: An examination of socio-cultural theory and inclusive practices and policy in New South Wales DET schools. Paper presented at the 2007 Learning and Socio-cultural Theory: Exploring Modern Vygotskian Perspectives International Workshop, Wollongong University, Wollongong, Australia.

Donnelly, V. (2005, August). Developing an effective assessment for learners with PMLD. Paper presented at the ISEC 2005 Conference, Glasgow, Scotland.

Dowrick, M.K. (2001). Educators, parents, students and researchers: Different voices but common agenda. Special Education Perspectives, 10(2), 24-36.

Dowrick, M.K. (2002). A model for assessing learning outcomes for Australian students in special schools. British Journal of Special Education, 29, 189-195. doi:10.1111/1467-8527.00268

European Agency for Development in Special Needs Education. (2009). Key principles for promoting quality in inclusive education: Recommendations for policy makers. Odense, Denmark: Author.

Ewing, R. (2010). Curriculum and assessment: A narrative approach. Melbourne, Australia: Oxford University Press.

Ferguson, D.L. (2008). International trends in inclusive education: The continuing challenge to teach one and everyone. European Journal of Special Needs Education, 2, 109-120. doi:10.1080/ 08856250801946236

Foreman, P. (Ed.). (2011). Inclusion in action (3rd ed.). Melbourne, Australia: Cengage Learning.

Foreman, P., \& Arthur-Kelly, M. (2005, August). Alertness levels and communication involvement in students with the most severe multiple disabilities in Australian classrooms: Effects of short teacher training programs. Paper presented at the ISEC 2005 Conference, Glasgow, Scotland.

Foreman, P., Arthur-Kelly, M., Pascoe, S., \& Smyth King, B. (2004). Evaluating the educational experiences of students with profound and multiple disabilities in inclusive and segregated classroom settings: An Australian perspective. Research and Practice for Persons with Severe Disabilities, 29, 183-193. doi:10.2511/rpsd.29.3.183

Forlin, C., Loreman, T., Sharma, U., \& Earle, C. (2009). Demographic differences in changing preservice teachers' attitudes, sentiments and concerns about inclusive education. International Journal of Inclusive Education, 13, 195-209. doi:10.1080/13603110701365356

Formosa, L., \& Dixon, R. (2004, December). The NSW DET's Quality Teaching framework and the realities of a special education classroom. Paper presented at the 2004 AARE National Conference, Melbourne, Australia.

Gardner, H., \& Traub, J. (1999, October 1). A debate on "multiple intelligences". Cerebrum. Retrieved December 2011 from http://www.dana.org/news/cerebrum/detail.aspx?id=3016

Garrett, P. (2011). Review of the Disability Standards for Education. Canberra: Government of Australia.

Gómez, L.E., Verdugo, M. A., Arias, B., \& Arias, V. (2011). A comparison of alternative models of individual quality of life for social service recipients. Social Indicators Research, 101, 109-126. doi:10.1007/s11205010-9639-y

Government of Britain. (2009). The P Scales: Level descriptors P1 to P8. London, UK: Author.

Government of Ireland. (2006). Quest for Learning: Guidance and assessment materials - Profound and multiple learning difficulties. Dublin, Ireland: Author. 
Hewett, D. (2009, October). Intensive interaction: Priorities and principles for teaching communication to pupils with PIMD. Paper presented at the 2009 CCEA Conference, England.

Hogg, J. (2007). Complex needs and complex solutions: The challenge of profound intellectual and multiple disabilities. Journal of Policy and Practice in Intellectual Disabilities, 4, 79-82. doi:10.1111/j.17411130.2007.00103.x

Imray, P. (2011). The Bridge School curriculum document for pupils with profound and multiple learning difficulties. Unpublished manuscript.

Imray, P., Gazquez, D., \& Bond, L. (2010). A PMLD curriculum for the 21st century. The SLD Experience, $58,11-17$.

International Association for the Scientific Study of Intellectual Disabilties (IASSID). (2011). Profound multiple disabilities mission statement. Retrieved December 2011 from https://www.iassid.org/sirgs/profound-multiple-disabilities

Jackson, L. (1993). Elements of a theoretical structure that will support best practices in communication facilitation. The Journal of the Association for Persons with Severe Handicaps, 18, 143-160.

Jones, P.M. (2010). My peers have also been an inspiration to me: Developing online learning opportunities to support teacher engagement with inclusive pedagogy for students with severe/profound intellectual developmental disabilities. International Journal of Inclusive Education, 14, 681-696. doi:10.1080/13603111003778452

Karakoski, J. (2008). The reform of education for students with special educational needs in South Eastern Europe: Lessons and experiences from Finland's bilateral support. Helsinki: Ministry of Foreign Affairs of Finland.

Killen, R. (2005). Programming and assessment for quality teaching and learning. Melbourne, Australia: Thomson.

Konza, D. (2008). Inclusion of students with disabilities in new times: Responding to the challenge. Research Online. Retrieved May 2011 from http://ro.uow.edu.au/edupapers/36/

Kosky, C., \& Curtis, R. (2008). An action research exploration integrating student choice and arts activities in a sixth grade social studies classroom. Journal of Social Studies Research, 32(1), 22-27.

Krause, K.-L., Bochner, S., Duchesne, S., \& McMaugh, A. (2010). Educational psychology for learning and teaching (3rd ed.). Melbourne, Australia: Cengage Learning.

Lachs, J. (1986). Response: Biological being and quality of life. In P.R. Dokecki \& R.M. Zaner (Eds.), Ethics of dealing with persons with severe handicaps: Toward a research agenda (pp. 93-96). Baltimore, MD: Brookes.

Loftus, P., Ware, J., \& Donnelly, V. (2005, August). Developing an effective pedagogy for pupils with PMLD: The development of a route map for assessing learners with multiple disabilities. Paper presented at the ISEC 2005 Conference, Glasgow, Scotland.

Longhorn, F. (2002). Assessing happiness for very special learners. The SLD Experience, 33, 21-23.

Lyons, G. (2003, January). How about a FUNctional curriculum? An alternative approach to the education of students with profound and multiple disabilities. Paper presented at the 2003 International Congress for School Effectiveness and Improvement, Sydney, Australia.

Lyons, G. (2004). Life satisfaction for children with profound multiple disabilities (Unpublished doctoral dissertation). The University of Newcastle, Australia.

Lyons, G. (2010). Quality of life for persons with intellectual disabilities: A review of the literature. In R. Kober (Ed.), Enhancing the quality of life of people with intellectual disabilities: From theory to practice (Social Indicators Research Series, Vol. 41, pp. 73-126). Dordrecht, the Netherlands: Springer.

Lyons, G., \& Cassebohm, M. (2011). Curriculum development for students with profound intellectual and multiple disabilities: How about a quality of life focus? Special Education Perspectives, 12(2), 24-39.

McGill, P., Tennyson, A., \& Cooper, V. (2006). Parents whose children with learning disabilities and challenging behaviour attend 52-week residential schools: Their perceptions of services received and expectations of the future. British Journal of Social Work, 36, 597-616. doi:10.1093/bjsw/bch297

Ministerial Council on Education, Employment, Training and Youth Affairs. (2008). Melbourne declaration on educational goals for young Australians. Melbourne, Australia: Author. 
Morris, I. (2009). Teaching happiness and well-being in schools: Learning to ride elephants. London, UK: Continuum.

Munde, V.S., Vlaskamp, C., Ruijssenaars, A., \& Nakken, H. (2011). Determining alertness in individuals with profound intellectual and multiple disabilities: The reliability of an observation list. Education and Training in Autism and Developmental Disabilities, 46, 116-123.

National Dissemination Center for Children with Disabilities. (2011). Related services. Unpublished manuscript.

Nelson, C., van Dijk, J., McDonnell, A.P., \& Thompson, K. (2002). A framework for understanding young children with severe multiple disabilities: The van Dijk approach to assessment. Research and Practice for Persons with Severe Disabilities, 27, 97-111. doi:10.2511/rpsd.27.2.97

Nietupski, J., Hamre-Nietupski, S., Curtin, S., \& Shrikanth, K. (1997). A review of curricular research in severe disabilities from 1976 to 1995 in six selected journals. Journal of Special Education, 31, 36-55. doi:10.1177/002246699703100104

NSW Department of Education and Training (NSW DET). (2005). Policy standards for curriculum planning and programming, assessing and reporting to parents K-12. Sydney, Australia: Author.

NSW Department of Education and Training (NSW DET). (1991). Programming communication for students with severe intellectual disability. Sydney, Australia: Author.

NSW Disability Discrimination Legal Centre Inc. (2010). Submission: Inquiry into provision of education to students with a disability or special needs. Unpublished manuscript.

Pagliano, P. (2006). The importance of humour for children. Unpublished manuscript.

Pepper, D. (2007). Assessment for disabled students: An international comparison (QCA Briefing Document). London, UK: Qualifications and Curriculum Authority.

Perez, L., \& Dominguez, P. (2005). Cognitive stimulation via the model of multiple intelligences. In P.A. Tripero (Ed.), Specific special education needs and attention to diversity (pp. 109-140). Madrid, Spain: Consejeria of Education.

Public Schools Principals Forum. (2009). Provision of services for special needs/disabled students in NSW. Sydney, Australia: Author.

Qualifications and Curriculum Development Agency. (2009). Primary curriculum review: Curriculum reform consultation report to the DCSF. London, UK: Author.

Qualifications and Curriculum Development Agency. (2011). P scales factsheet. London, UK: Author.

Renzaglia, A., \& Dymond, S.K. (2005, August). Accessing general curriculum for high school students with significant cognitive disabilities. Paper presented at the ISEC 2005 Conference, Glasgow, Scotland.

Roberts, J., \& Ridley, G. (2009). Review of programs and services currently provided through Kingsdene School and Kingsdene Residential Services. Sydney: Anglicare Australia.

Rogers, C. (2007). Experiencing an 'inclusive' education: Parents and their children with 'special educational needs'. British Journal of Sociology of Education, 28, 55-68. doi:10.1080/01425690600996659

Ryndak, D.L., Moore, M.A., Orlando, A.M., \& Delano, M. (2008). Access to the general curriculum: The mandate and role of context in research-based practice for students with extensive support needs. Research and Practice for Persons with Severe Disabilities, 33, 199-214.

Sabatino, D.A., Miller, P.F., \& Schmidt, C. (1981). Can intelligence be altered through cognitive training? The Journal of Special Education, 15, 125-144. doi:10.1177/002246698101500205

Sailor, W. (2008). Access to the general curriculum: Systems change or tinker some more? Research and Practice for Persons with Severe Disabilities, 33, 249-258.

Saloviita, T. (2009). Inclusive education in Finland: A thwarted development. Unpublished manuscript.

Shearer, J. (2010). Aspects of quality of life for children with a disability in inclusive schools. In R. Kober (Ed.), Enhancing the quality of life of people with intellectual disabilities: From theory to practice (Social Indicators Research Series, Vol. 41, pp. 205-221). Dordrecht, the Netherlands: Springer. doi:10.1007/978-90-481-9650-0_13

Siegal, E., \& Allinder, R.M. (2005). Review of assessment procedures for students with moderate and severe disabilities. Education and Training in Developmental Disabilities, 40, 343-352. 
Sigafoos, J., Moore, D., Brown, D., Green, V.A., O’Reilly, M.F., \& Lancioni, G.E. (2010). Special education funding reform: A review of impact studies. Australasian Journal of Special Education, 34, 17-35. doi:10.1375/ajse.34.1.17

Simmons, B., \& Bayliss, P. (2007). The role of special schools for children with profound and multiple learning difficulties: Is segregation the way? British Journal of Special Education, 34, 19-24. doi:10.1111/j.1467-8578.2007.00449.x

Slee, R. (2008). Beyond special and regular schooling? An inclusive education reform agenda. International Studies in Sociology of Education, 18, 99-116. doi:10.1080/09620210802351342

Slee, R. (2011). The irregular school: Exclusion, schooling and inclusive education. Abingdon, UK: Routledge.

Smith, A. (with Jones, J., \& Kurlbaum, J.) (2010). Winning the $H$ factor: The secrets of happy schools. London, UK: Continuum.

Smith, B. (1996). Discussion: Age-appropriateness or developmentally-appropriate activities? In J. Coupe O'Kane \& J. Goldbart (Eds.), Whose choice? Contentious issues for those working with people with learning difficulties. London, UK: David Fulton.

Smith, P. (2007). Have we made any progress? Including students with intellectual disabilities in regular eduation classrooms. Intellectual and Developmental Disabilities, 45, 297-309. doi:10.1352/00476765(2007)45[297:HWMAPI]2.0.CO;2

Snell, M. (2008). Rethinking effective instructional practices: A response to Copeland and Cosbey. Research and Practice for Persons with Severe Disabilities, 33, 228-231.

Soresi, S., Nota, L., \& Wehmeyer, M.L. (2011). Community involvement in promoting inclusion, participation and self-determination. International Journal of Inclusive Education, 15, 15-28. doi:10.1080/13603116.2010.496189

Stephenson, J. (2006). Intellectual quality for students with severe intellectual disability. Paper presented at the AARE 2005 International Education Research Conference, Parramatta Campus of the University of Western Sydney, Australia. Retrieved from http://www.aare.edu.au/05pap/ste05118.pdf

Stolk, J. (2000). Experience of meaning in daily care for people with mental retardation. In J. Stolk, T.A. Boer, \& R. Seldenrijk (Eds.), Meaningful care: A multidisciplinary approach to the meaning of care for people with mental retardation (pp. 167-182). Dordrecht, the Netherlands: Kluwer Academic.

Stolk, J., Boer, T.A., \& Seldenrijk, R. (Eds.). (2000). Meaningful care: A multidisciplinary approach to the meaning of care for people with mental retardation. Dordrecht, the Netherlands: Kluwer Academic.

Vos, P., De Cock, P., Petry, K., Van Den Noorgate, W., \& Maes, B. (2010). What makes them feel like they do? Investigating the subjective well-being in people with severe and profound disabilities. Research in Developmental Disabilities, 31, 1623-1632. doi:10.1016/j.ridd.2010.04.021

Ware, J., \& Donnelly, V. (2004). Assessment for learning for pupils with PMLD: The ACCAC Insight Project. PMLD Link, 16(3), 12-18.

Welsh Assembly Government. (2006a). Routes for learning: Additional guidance. Cardiff: Author.

Welsh Assembly Government. (2006b). Routes for learning: Assessment booklet. Cardiff: Author.

Westwood, P., \& Graham, L. (2003). Inclusion of students with special needs: Benefits and obstacles as perceived by teachers in New South Wales and South Australia. Australian Journal of Learning Disabilities, 8(1), 3-15. doi:10.1080/19404150309546718 